\title{
Pectus excavatum repair improves respiratory pump efficacy and cardiovascular function at exercise
}

\author{
Remi Neviere, MD, PhD, ${ }^{\mathrm{a}}$ Lotfi Benhamed, MD, ${ }^{\mathrm{b}}$ Anju Duva Pentiah, $\mathrm{MD},{ }^{\mathrm{c}}$ and Alain Wurtz, MD, \\ Lille, France
}

The action of the respiratory muscle during inspiration expands the chest, which lowers the pressure in the thoracic cavity. The lower pressure allows for increased venous return, heart filling, and cardiac output, the so-called respiratory blood pump. Chest deformity such as pectus excavatum (PEx) can alter the development of negative pulmonary pressure, which could explain the impaired cardiovascular function., ${ }^{1,2}$ Because cardiovascular function is the limiting factor for oxygen delivery to the tissues at maximal exercise, we hypothesized that the reduced aerobic capability in patients with PEx could be the result of impaired inspiratory muscle strength to generate negative pulmonary pressure, thus limiting venous return and cardiac output. Specifically, we tested whether PEx deformity would be associated with reduced respiratory muscle strength, as evaluated by the maximal inspiratory pressures, and whether surgery would improve the aerobic capacity by the increased respiratory pump efficacy and better cardiovascular adaptation.

From the Service d'Explorations Fonctionnelles Respiratoires EFR Hôpital Calmette CHU Lille, ${ }^{\text {a }}$ Lille, France; Clinique de Chirurgie Cardiaque et Thoracique Hôpital Calmette CHU Lille, ${ }^{\mathrm{b}}$ Lille, France; and Service d'Explorations Fonctionnelles Cardiovasculaires EFCV Hôpital Cardiologique CHU Lille, ${ }^{c}$ Lille, France.

Disclosures: Authors have nothing to disclose with regard to commercial support. Received for publication March 29, 2012; revisions received July 9, 2012; accepted for publication July 30, 2012; available ahead of print Aug 27, 2012.

Address for reprints: Remi Neviere, MD, PhD, Service d'Explorations Fonctionnelles Respiratoires EFR Hôpital Calmette, CHRU Lille, Bd Pr Leclercq, Lille 59000,

France (E-mail: rneviere@univ-lille2.fr).

J Thorac Cardiovasc Surg 2013;145:605-6

$0022-5223 / \$ 36.00$

Copyright (c) 2013 by The American Association for Thoracic Surgery

http://dx.doi.org/10.1016/j.jtcvs.2012.07.078

\section{PATIENTS AND METHODS}

Candidates for PEx repair (Ravitch type procedure) underwent, at inclusion and 1 year after surgery (January 2010 to December 2011), transthoracic echocardiography, chest computed tomography, spirometry, and incremental exercise testing. Inspiratory muscle strength was evaluated by the mean of the maximal static respiratory pressure (PImax) and sniff nasal inspiratory pressure (SNIP). ${ }^{3}$ SNIP consists of measuring the peak nasal pressure in 1 occluded nostril during a maximal sniff performed from relaxed end-expiration through the contralateral patent nostril. SNIP closely reflects the esophageal pressure and, therefore, inspiratory muscle strength. Oxygen uptake $\left(\mathrm{VO}_{2}\right)$ and oxygen pulse $\left(\mathrm{VO}_{2} /\right.$ heart rate) were evaluated during exercise performed on a cycloergometer until exhaustion. Statistical analysis was performed using a software program (SPSS, version 12.0, SPSS, Inc, Chicago, Ill) that allows the calculation of the mean and standard deviation, as well as Student's paired $t$-tests and multiple regression analysis. Multivariate analysis of patient characteristics (age, gender, weight, Haller index, forced expiratory volume in $1 \mathrm{~s}$, forced vital capacity, total lung volume, PImax, SNIP, maximum heart rate) was performed.

\section{RESULTS}

Twenty patients were included in the study. The mean \pm SD age was $32 \pm 11$ years, and the PEx severity index (Haller index) was $4.7 \pm 1.4$. At follow-up $(12 \pm 0.6$ months), measurements of body weight $(65 \pm 9 \mathrm{~kg})$ and exertion habit $(1.5 \pm 1 \mathrm{~h} / \mathrm{wk})$ were unchanged compared with the preoperative values. The echocardiographic findings were normal. The predicted values of spirometry and lung volumes were slightly reduced, yet within the normal range (Table 1). The PImax and SNIP were significantly reduced (Table 1). At submaximal exercise, patients with PEx have reduced peak $\mathrm{VO}_{2}$ and peak oxygen pulse (Table 1). Compared with preoperative measurements, postoperative static pulmonary function was not affected, although PImax and SNIP were markedly increased (Table 1). Postoperative

TABLE 1. Pre- and postoperative values of observed pulmonary function tests $(\mathbf{n}=20)$

\begin{tabular}{|c|c|c|c|}
\hline Variable & Preoperative & Postoperative & $P$ value \\
\hline $\mathrm{FVC}(\mathrm{L})$ & $4.7 \pm 0.7(91 \% \pm 4 \%)$ & $4.5 \pm 0.8(90 \% \pm 4 \%)$ & .40 \\
\hline $\mathrm{FEV}_{1}(\mathrm{~L})$ & $3.9 \pm 0.8(94 \% \pm 2 \%)$ & $3.9 \pm 0.9(94 \% \pm 2 \%)$ & .90 \\
\hline TLV (L) & $6.8 \pm 1.2(95 \% \pm 3 \%)$ & $6.7 \pm 1.4(95 \% \pm 3 \%)$ & .81 \\
\hline PImax $\left(\mathrm{cm} \mathrm{H}_{2} \mathrm{O}\right)$ & $79 \pm 21(76 \% \pm 16 \%)$ & $90 \pm 17(88 \% \pm 10 \%)$ & $<.01$ \\
\hline $\mathrm{SNIP}\left(\mathrm{cm} \mathrm{H} \mathrm{H}_{2} \mathrm{O}\right)$ & $69 \pm 19(70 \% \pm 13 \%)$ & $77 \pm 18(78 \% \pm 14 \%)$ & $<.01$ \\
\hline $\mathrm{VO}_{2}(\mathrm{~mL} / \mathrm{kg} / \mathrm{min})$ & $30.8 \pm 6.9(73 \% \pm 10 \%)$ & $34.4 \pm 8.6(82 \% \pm 11 \%)$ & $<.01$ \\
\hline $\mathrm{RER}\left(\mathrm{VCO}_{2} / \mathrm{VO}_{2}\right)$ & $1.22 \pm 0.14$ & $1.23 \pm 0.11$ & .80 \\
\hline HR (beats/min) & $178 \pm 10(93 \% \pm 4 \%)$ & $171 \pm 12(91 \% \pm 6 \%)$ & .06 \\
\hline Oxygen pulse (mL/beat) & $11.5 \pm 3.2(80 \% \pm 12 \%)$ & $12.9 \pm 3.5(91 \% \pm 14 \%)$ & $<.05$ \\
\hline
\end{tabular}

Data presented as mean $\pm \mathrm{SD}$ (20 patients), with data in parentheses percent of predicted values. $F V C$, Forced vital capacity; $N S$, not significant; $F E V_{I}$, forced expiratory volume in $1 \mathrm{~s} ; T L V$, total lung volume; PImax, maximal static respiratory pressure; $S N I P$, sniff nasal inspiratory pressure; $V \mathrm{O}_{2}$, oxygen uptake; $V C \mathrm{O}_{2}$, carbon dioxide production; $R E R$, respiratory exchange ratio; $H R$, heart rate. 


$$
\mathrm{O}_{2} \text { pulse and SNIP relationship }
$$

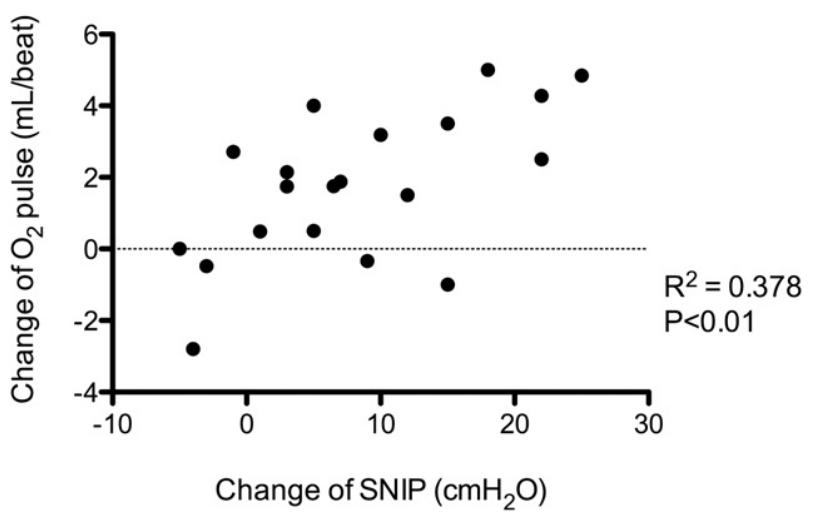

FIGURE 1. Relationship between changes in oxygen pulse and sniff nasal inspiratory pressure $(S N I P)$. Axes represent difference between post- and preoperative values.

exercise testing displayed significant improvement in the anaerobic threshold, peak $\mathrm{VO}_{2}$, and peak oxygen pulse. Positive correlations were found between postoperative changes for oxygen pulse and PImax $\left(r^{2}=0.23 ; P=.04\right)$ and for oxygen pulse and SNIP $\left(r^{2}=0.38 ; P<.01\right.$; Figure 1). SNIP was the strongest independent predictor factor of oxygen pulse increase after PEx repair, and adding age, weight, Haller index, and pulmonary function test results to the regression equation did not increase the correlation coefficient $\left(r^{2}=0.378\right)$.

\section{DISCUSSION}

The major new findings from our study are twofold. First, preoperative PImax and SNIP were reduced in patients with PEx, suggesting weakness of inspiratory muscle strength. Second, our study has confirmed that exercise tolerance is impaired in patients with PEx and is associated with a reduced oxygen pulse, a noninvasive surrogate of ventricular stroke volume. One year after open chest PEx repair, the PImax and SNIP had increased, suggesting improved capacity of the inspiratory muscle system to generate intrathoracic negative pressure. Positive correlations between postoperative changes of inspiratory pressures (PImax and SNIP) and oxygen pulse suggest that reduced respiratory pump efficiency participated, at least in part, in the cardiovascular limitation during exercise. A study limitation was that during a 1-year interval, the patients' conditioning could have improved, which would have increased the oxygen pulse, independent of the stroke volume. However, we ascertained that their exertion habit was unchanged.

\section{References}

1. Morshuis WJ, Folgering HT, Barentsz JO, Cox AL, van Lier HJ, Lacquet LK. Exercise cardiorespiratory function before and one year after operation for pectus excavatum. J Thorac Cardiovasc Surg. 1994;107:1403-9.

2. Neviere R, Montaigne D, Benhamed L, Catto M, Edme JL, Matran R, Wurtz A. Cardiopulmonary response following surgical repair of pectus excavatum in adult patients. Eur J Cardiothorac Surg. 2011;40:e77-82.

3. Flaminiano LE, Celli BR. Respiratory muscle testing. Clin Chest Med. 2001;22: 661-77. 